Second International Symposium on "Frying of Food"

First Announcement and Call for Poster Presentations

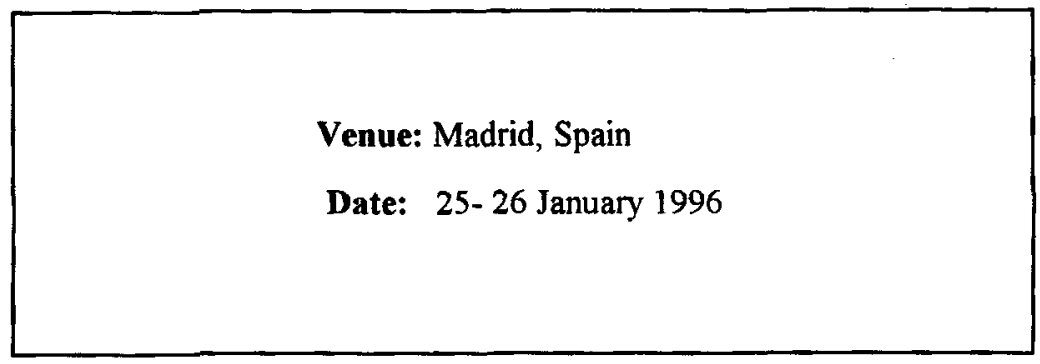

Organized by:

Official languages:

Topics include:

For further information contact:
Fundación Española de la Nutrición and the International Olive Oil Council

\section{English and Spanish}

The Frying Process: physical and physico-chemical aspects; frying technology - continuous, discontinuous, catering Changes in Frying Fats: analytical evaluation; repeated fryings; influence of minor components and additives; legislation

Changes in Fried Foods: energy, macronutrients and micronutrients; palatability; comparative study of frying and other cooking techniques; influence of the different factors involved in the process - food coatings, food volume:area ratio and fat:food ratio

Frying and Health: update on the role of frying in the prevention of some degenerative diseases; frying in the Mediterranean Diet; frying of food: quantity and quality of fat intake; epidemiology of the possible relationship between frying and health

D. José Manuel Avila, Fundación Española de la Nutrición, General Yagüe, 20, $4^{\circ} \mathrm{A}$, 28020 Madrid, Spain

Tel: +3415560163,+3415974405

Fax: +3415974404 
Announcement

TEMA-9

Ninth International Symposium on Trace Elements in Man and Animals

Venue: Banff, Alberta, Canada

Date: 19 - 24 May 1996

The aims of the symposium are: (1) to provide a forum at which recent progress in studies on the metabolism and functional roles of trace elements could be discussed and (2) to provide an opportunity for an exchange of ideas between workers investigating these fundamental aspects of the biological function of trace elements and those whose task it is to apply their findings in the field of nutrition, human or veterinary medicine, agriculture, biology, ecology and protection of the environment.

The symposium program will comprise oral presentations, poster sessions, scientific sessions and workshops.

Official language:

For Conference registration and information contact:
English

The Banff Centre for Conferences,

PO Box 1020,

Station 11,

Banff,

Alberta,

CANADA

TOL OCO

Tel: (403) $762-6308$

Fax: (403) $762-6388$

Email: RESERVATIONS\&BANFFCENTRE.AB.CA 